\title{
DFT Evaluation of Reactivity of $\beta$-Substituted meso-Bromoporphyrins towards Nucleophilic Substitution
}

\author{
Kirill P. Birin, ${ }^{\mathrm{a} @}$ Yulia G. Gorbunova, ${ }^{\mathrm{a}, \mathrm{b}}$ and Aslan Yu. Tsivadze ${ }^{\mathrm{a}, \mathrm{b}}$ \\ Dedicated to Full member of RAS Irina P. Beletskaya on occasion of her Anniversary
}

\author{
${ }^{a}$ A.N. Frumkin Institute of Physical Chemistry and Electrochemistry RAS, 119071 Moscow, Russia \\ ${ }^{\mathrm{b}}$ N.S. Kurnakov Institute of General and Inorganic Chemistry RAS, 119991 Moscow, Russia \\ ${ }^{\circledR}$ Corresponding author E-mail: kirill.birin@gmail.com
}

\begin{abstract}
The electronic structure of 15 model 5-bromoporphyrins was investigated by means of DFT B3LYP method. The comparison of the relative energy and the frontier molecular orbitals localization allowed the elucidation of the influence of the $\beta$-substituents electronic origin onto the electronic structure of the molecule. The obtained data is valuable for the evaluation of the relative reactivity of the 5-bromoporphyrins in the nucleophilic substitution reactions.
\end{abstract}

Keywords: Bromoporphyrins, nucleophilic substitution, DFT calculation.

\section{Анализ реакционной способности $\beta$-замещенных мезо-бромпорфиринов методом DFT}

\author{
К. П. Бирин, ${ }^{a}$ Ю. Г. Горбунова, ${ }^{a, b}$ А. Ю. Цивадзе \\ Посвящается Академику РАН И. П. Белецкой по случаю ее юбилея

\begin{abstract}
${ }^{a}$ Институт физической химии и электрохимии им. А.Н. Фрумкина РАН, 119071 Москва, Россия
' Институт общей и неорганической химии им. Н.С. Курнакова РАН, 119991 Москва, Россия

${ }^{\circledR}$ E-mail: kirill.birin@gmail.com
\end{abstract}

\begin{abstract}
В работе методом DFT ВЗLYP изучено электронное строение 15 модельных 5-бромпорфиринов. Сравнение энергии, симметрии и локализаџии вакантных орбиталей позволило оценить влияние $\beta$-заместителей на электронное строение молекул. На основе анализа результатов расчетов предложен подход, позволяющий предсказывать относительную реакиионную способность 5-бромпорфиринов при взаимодействии с нуклеофилами.
\end{abstract}

Ключевые слова: Бромпорфирины, нуклеофильное замещение, DFT расчет.

\section{Introduction}

Porphyrins and their metal complexes attract the interest of researchers as precursors of polyfunctional molecular blocks. Tremendous efforts were made by now for the development of methodologies for the targeted preparation of the substituted porphyrin derivatives. ${ }^{[1]}$ These approaches could be reasonably divided into two major groups, namely the preparation of the target porphyrins from functionalized building blocks and the post-functionalization of the available porphyrin macrocycle. The latter approach can be mentioned as more efficient one since the symmetrical porphyrins are readily available on the gram scale. Moreover, the substituted porphyrin precursors, namely $\beta$-substituted pyrroles, possess low stability.

Metal-promoted cross-coupling reactions have revealed the outstanding potential for the post-functionalization of porphyrins ${ }^{[2]}$ since the corresponding halo-substituted substrates are easily accessible by halogenation of the porphyrin macrocycle. Despite the versatility of this approach, the expenses of the noble-metal catalysts and phosphine ligands can be mentioned as its considerable drawbacks. Note- 
worthy, the preparation of compounds for further medicinal or biological investigations disfavors the use of noble metals in the synthesis because of their toxicity and requirements for their further removal. In this respect the application of common organic transformations in the chemistry of porphyrins represents an attractive route to avoid the contamination of the final products with toxic metal ions. Thus, the experimental implementations of the nucleophilic reactions in the porphyrin chemistry are reported by now for the introduction of mesoand $\beta$-substituents. ${ }^{[3-5]}$ These transformation include addition and substitution reactions with various substrates and reagents.

A set of efficient transformations was reported by Senge, consisting in nucleophilic addition of organometallic reagents to the porphyrin core, followed by oxidation, quenching or interaction of the formed anion with electrophiles. ${ }^{[3,4,6-12]}$ The interaction of meso- and $\beta$-nitroporphyrins with various nucleophiles was reported by Crossley and developed into an efficient synthetic tool. ${ }^{[5,13,14]}$ In the course of that research the authors have revealed and reported the unexpected significant influence of the substrate structure and reaction conditions onto the path and selectivity of the interaction. [13] Thus, the nucleophilic substitution reactions were also used as an alternative to the Buchwald-Hartwig amination for the preparation of the amino-substituted porphyrins providing the yields of the products $c a .50-95 \% .^{[15-19]}$ While the presence of electron-withdrawing groups in the substrate molecule facilitates the transformation, the inactivated bromo-substituted porphyrins were also successfully introduced into the reaction. The interaction of porphyrins with $\mathrm{O}-, \mathrm{S}-$ and N-nucleophiles allowed preparation of the corresponding substituted derivatives with high yields. ${ }^{[20-22]}$

Despite the wide potential of experimental implementations the nucleophilic reactions remain virtually unstudied from the mechanistic point. The polarizability of the porphyrin polyaromatic system is the key factor for the versatility of these substrates. Thus, the prediction of the selectivity and the influence of the peripheral substituents are difficult from the general positions, e.g. the theory of resonant structures. The density functional theory (DFT) calculations may allow to fill the voids in several cases and rationalize the structural peculiarities and reaction paths in these transformations. ${ }^{[23,24]}$ While the precise analysis of the energy characteristics, transition states and the reaction paths are significantly time-consuming procedures, our research was targeted in the different direction, namely the application of the relatively easy and available level of theory for the analysis of the tendencies in the porphyrin nucleophilic substitution reactions. ${ }^{[23]}$

Our current research is focused on the development of approaches for the transformation of the periphery of the porphyrin macrocycle by means of metal-promoted methods ${ }^{[25]}$ as well as condensation and substitution transformations. ${ }^{[26-29]}$ Thus, we have developed approaches for the preparation of meso-alkoxy- and meso-aryloxyporphyrins by means of nucleophilic substitution reaction ${ }^{[26]}$ and performed the quantum-chemical investigation of its selectivity. ${ }^{[23]}$ Thus, in mentioned work we have shown that the application of B3LYP 6-31G* level of theory for the analysis of the characteristics of frontier orbitals allows to estimate the reaction path of the nucleophilic reaction. The analysis of the influence of the electronic nature of the substituents in the opposite posi- tion of the macrocycle with respect to the leaving group allowed the prediction and explanation of the synthetic peculiarities. The obtained results were in consistency with the published data and were proved experimentally. ${ }^{[26]}$ In present work we have undertaken further investigation of the mutual influence of the substituents onto the energy and localization of the frontier orbitals of the 5-bromoporphyrin macrocycle and thus its reactivity in the nucleophilic substitution reactions.

\section{Experimental}

Quantum-chemical calculations were performed with Spartan'10 program package (build 1.1.0, Wavefunction Inc.) under Windows 7 operating system. The structures were found by convergence to equilibrium geometry at an energy minimum with default values of gradient tolerance $\left(4.5 \cdot 10^{-4}\right.$ hartree.bohr $\left.{ }^{-1}\right)$ and distance tolerance $\left(1.8 \cdot 10^{-3} \AA\right)$. The DFT calculations were performed at B3LYP level of theory with $6-31 \mathrm{G}(\mathrm{d})$ basis set. The starting structures for calculation were prepared by minimization with semi-empirical PM6 method. The vibrational frequencies were calculated for all minimized structures to prove the absence of the imaginary frequencies.

\section{Results and Discussion}

In order to reveal the influence of the electronic nature of the substituents at the 7,8,12 and 13 positions of the porphyrin macrocycle onto the reactivity of the meso-bromo-fragment the frontier orbitals of a set of model molecules were calculated (Figure 1). The introduction of methoxy- and cyano-groups to the mentioned positions was considered. $\beta$-Substituted 5,15-dibromoporphyrins were used in the calculation as well as the $\beta$-derivatives of the inactivated 5-bromo-15-methoxyporphyrin. The evaluation of the relative reactivity of the model compounds was performed by comparing the characteristics of their frontier orbitals with the previously reported theoretical ${ }^{[23]}$ and experimental ${ }^{[26]}$ data. Thus, we have previously reported, that the introduction of the donor substituents to 15 -position of the porphyrin core significantly decreases the reactivity of the 5-bromo-substituent towards nucleophilic attack. In this respect similar influence of the donor substituents at $\beta$-positions could be expected. On the other hand it is known that the conjugation core of the porphyrin macrocycle may not include $\beta$-positions of the two opposite pyrrolic rings and thus diminish the influence of substituents in these positions. In this respect the straightforward prediction of the influence of $\beta$-substitution is impossible. Nevertheless the comparison of the energy levels of the molecules under consideration with the ones of the reference molecules may allow determination of the activation or inactivation of the substrate.

Obviously, the energy of LUMO is a key factor for the prediction of reactivity of the molecule in the nucleophilic reactions under orbital control. As we have already reported, the increase of the energy of the unoccupied orbital corresponds to decrease of reactivity of the substrate as concluded by the comparison with published experimental data. ${ }^{[23]}$ With this consideration we have analyzed the relative energy levels of the model compounds. Figure 2 shows the dependence of the energy levels of LUMO and LUMO+1 of the 5,15-dibromoporphyrins $\mathbf{4}$ and $\mathbf{5}$, bearing $\beta$-methoxy 


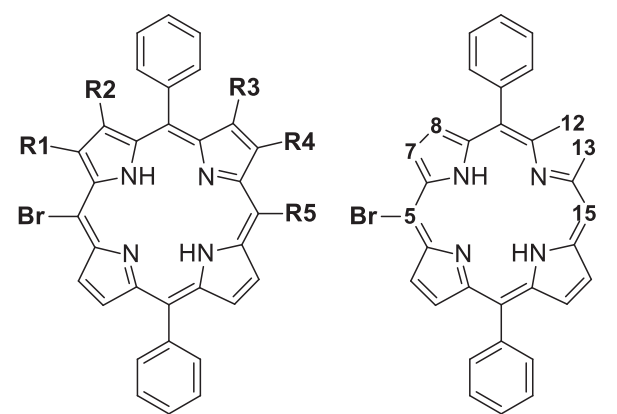

1, R1=R2=R3=R4=H, R5=CN

2, R1=R2=R3=R4=H, R5=Br

3, R1=R2=R3=R4=H, R5=OMe

4, R1=OMe, R2=R3=R4=H, R5=Br

5, R2=OMe, R1=R3=R4=H, R5=Br

6. $\mathrm{R} 1=\mathrm{CN}, \mathrm{R} 2=\mathrm{R} 3=\mathrm{R} 4=\mathrm{H}, \mathrm{R} 5=\mathrm{Br}$

7, R2=CN, R1=R3=R4=H, R5 =Br

8, R1=OMe, R2=R3=R4=H, R5=OMe

9, R2=OMe, R1=R3=R4=H, R5=OMe

10, R3=OMe, R1=R2=R4=H, R5=OMe

11, R4=OMe, R1=R2=R3=H, R5=OMe

12, R1=CN, R2=R3=R4=H, R5=OMe

13, R2=CN, R1=R3=R4=H, R5=OMe

14, R3=CN, R1=R2=R4=H, R5=OMe

15, R4=CN, R1=R2=R3=H, R5=OMe

Figure 1. The designation of the substituents in the model compounds and the numbering of the porphyrin core. group in varied positions in comparison with reference molecules 1-3. It can be easily observed that decrease of electronwithdrawing properties of the 15-substituent in the 1-3 series gradually increases the energy of the unoccupied orbitals, reaching the maximum value with compound $\mathbf{3}$. The levels of LUMO in the case of $\mathbf{4}$ and $\mathbf{5}$ gradually decrease compared to 3 , that reflects the diminished influence of the $\beta$-substituent onto the reactivity compared to meso-ones. The comparison between models bearing $\mathrm{MeO}$-group in 7 and 8 positions reveals its lower influence onto the level of LUMO in the latter case. Considering the distribution of LUMO it can be easily found that position 8 possesses no increment into the orbital and thus the influence of the corresponding substituent is reduced. Nevertheless, the level of LUMO does not reach the corresponding energy level of $\mathbf{2}$, which does not contain any inactivating groups.

Next, we have analyzed the influence of the electronwithdrawing cyano-group in $\beta$-positions of porphyrin core of molecules 6 and 7 (Figure 3). The presence of electronwithdrawing group expectedly results in decrease of the energy of LUMO. It could be noted, that the levels of unoccupied orbitals are virtually unchanged upon changing the position of CN-group from 7 to 8. Moreover, the level of LUMO in both cases is slightly lower than the one in the case of $\mathbf{1}$, that indicates efficient activation of the substrate. The analysis of the distributions of LUMO of $\mathbf{6}$ and 7 reveals the difference in its localization comparing to the case $\mathbf{4}$ and $\mathbf{5}$. First, both positions 7 and 8 possess considerable increments

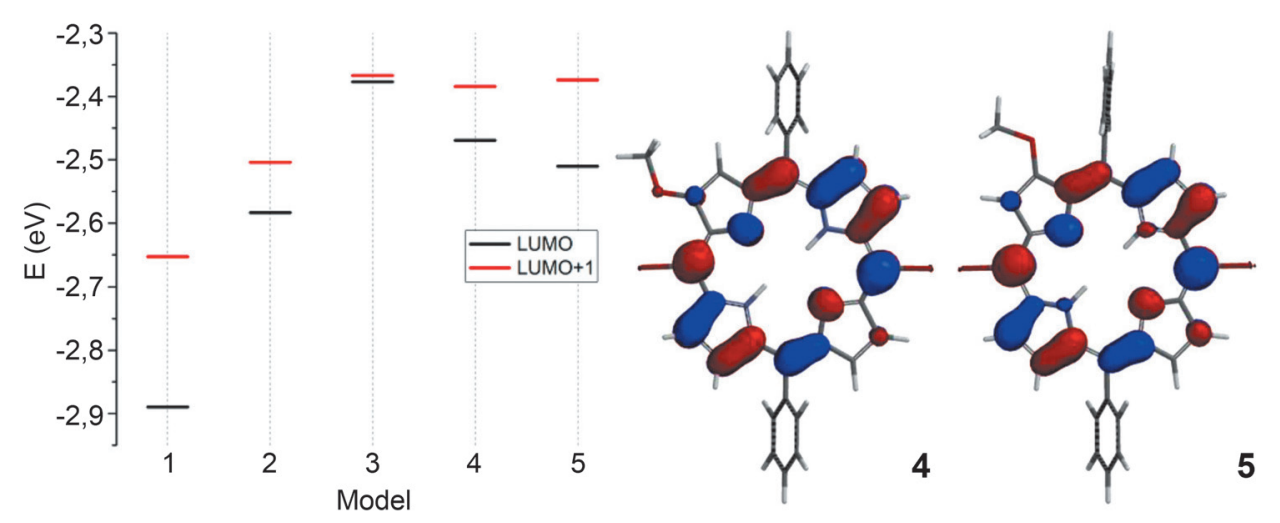

Figure 2. The relative energy of LUMO and LUMO+1 of porphyrins 1-5 and the localization of LUMO in 4 and 5.

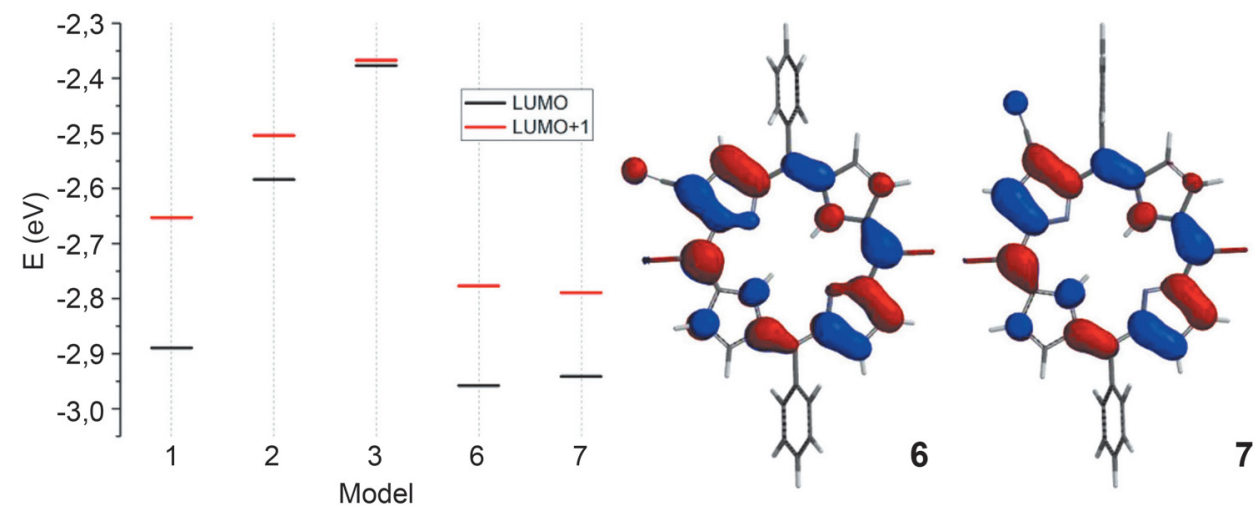

Figure 3. The relative energy of LUMO and LUMO+1 of porphyrins 1-3 and 6-7 and the localization of LUMO in 6 and 7. 
to LUMO despite the position of $\mathrm{CN}$-group. Next, in both cases the localization of LUMO includes the CN-group, testifying its conjugation and influence onto the orbital level.

Comparison of the orbital structure and energy levels of 4, 5 and 6,7 pairs of model molecules allows an unexpected conclusion. The introduction of the donor and acceptor fragments to $\beta$-positions of the porphyrin macrocycle results in increase and decrease of the energy levels of unoccupied orbitals, respectively. In terms of the previously found relationships it can be attributed to inactivation or activation of the corresponding substrate towards nucleophilic attack. However, the influence of these $\beta$-substituents could not be interpreted in a straightforward manner. It should be noted, that the introduction of the substituents with the opposite characteristics results in change of symmetry and distribution of the unoccupied orbitals. This polarizability of the porphyrin macrocycle leads unexpectedly to partial compensation of the inactivating influence of the electron-donor methoxy substituent, comparing to model molecule 3 , bearing methoxy-group at 15-position. In contrast, in the presence of electron-withdrawing $\beta$-cyanogroup the decrease of the orbital level and, consequently, the activation of the substrate could be considered higher than in the case of meso-substituted analogue $\mathbf{1 .}$

In order to evaluate the additivity of the influence of the inactivating electron-donor groups and to probe the difference in LUMO level upon introduction of methoxygroups to different $\beta$-positions we have analyzed the series of 5-bromo-15-methoxyporphyrins, containing additional methoxy-group at 7, 8, 12 or 13 positions of the core (porphyrins 8-11). In this series further increase of the energy levels of unoccupied orbitals is expected compared to inactivated model porphyrin 3 . The energy levels of unoccupied orbitals are represented at Figure 4.

The introduction of the additional electron-donor methoxy group to the $\beta$-positions of $\mathbf{3}$ providing model compounds 8-11 expectedly results in increase of the energy of unoccupied orbitals. Surprisingly, the energy levels of LUMO are virtually independent from the position of $\beta$-methoxy-group. Moreover, the energy gap between LUMO of $\mathbf{3}$ and 8-11 is smaller than the one between LUMO of $\mathbf{2}$ and $\mathbf{3}$, that could indicate the decreased influence of the $\beta$-substituents onto the reactivity of the substrates. The analysis of the distribution of LUMO of porphyrins 8-11 reveals the changes in its localization upon variation of the position of methoxy-group. Interestingly, the change of the position of $\beta$-methoxy-group leads to redistribution of LUMO and in each case the $\beta$-carbon atom bound to methoxy-group possesses no increment to the orbital. Moreover, the unoccupied orbital is not localized at the methoxy-fragment. Together these peculiarities explain the similar and low influence of the peripheral electron-donor group onto the characteristics of LUMO.

Furthermore, we have compared the contrary influence of meso- and $\beta$-substituents. The series of model compounds 12-15 is represented by inactivated 5-bromo-15-methoxyporphyrins bearing electron-withdrawing cyano-group at $\beta$-positions. The energy levels of the unoccupied orbitals are

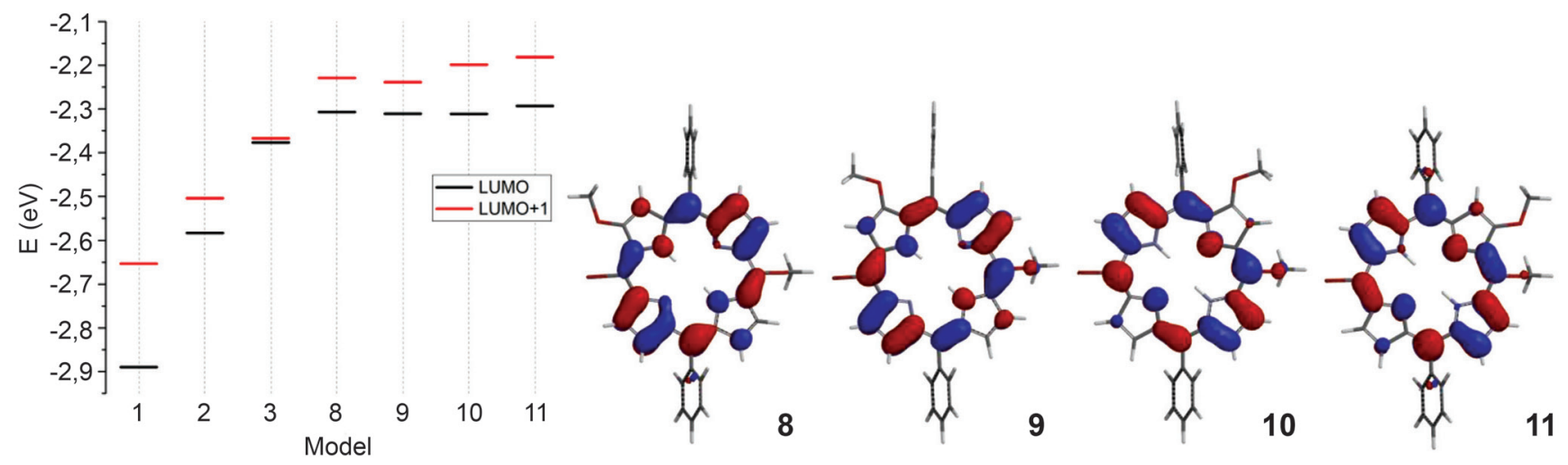

Figure 4. The relative energy of LUMO and LUMO+1 of porphyrins 1-3 and 8-11 and the localization of LUMO in 8-11.

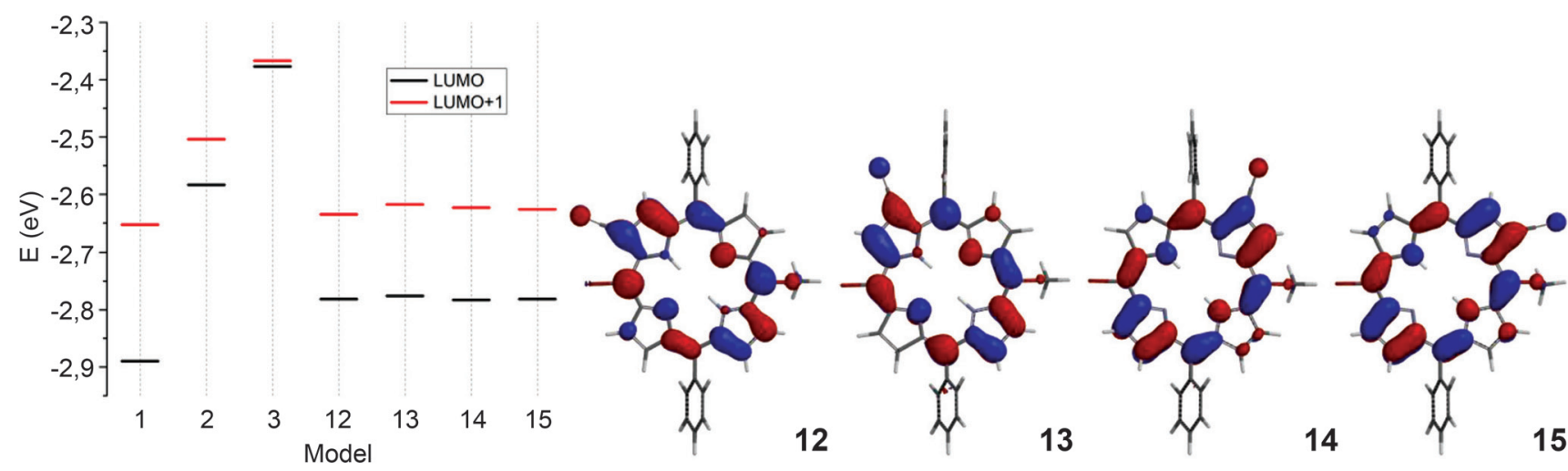

Figure 5. The relative energy of LUMO and LUMO+1 of porphyrins 1-3 and 12-15 and the localization of LUMO in 12-15. 
shown at Figure 5. In this respect the introduction of $\beta$-cyanosubstituent reasonably results in decrease of LUMO energy level that corresponds to activation of the substrate. Similarly to discussed above methoxy-substituted compounds 8-11 the levels of unoccupied orbitals are virtually independent from the position of the $\beta$-acceptor fragment. The comparison of distribution of LUMO allows to rationalize this peculiarity. Thus, in all cases the orbital is redistributed depending on the position of $\beta$-substituent and in all cases the cyano-group and the corresponding $\beta$-carbon atom possess considerable increments to the orbital. Thus, it can be concluded that despite the position of the $\beta$-acceptor moiety its influence onto the energy and symmetry of LUMO is valuable and remain virtually unchanged.

The performed calculations reveal that the polarizable polyaromatic system of the porphyrin core cannot be a subject of traditional prediction and rationalization of reactivity and selectivity in terms of resonant structures. In all cases despite the presence and position of electron-donor or withdrawing groups the reaction site carbon atom possesses the considerable increment to the unoccupied orbitals, while the energy level of LUMO is changed revealing the increase or loss of reactivity of the molecule. The introduction of $\beta$-substituents with different electronic properties leads to polarization and redistribution of the orbital and the influence of electron-reach and electron-deficient fragments is found to be significantly different. The experimental implementations of the developed prediction approach would be the topic of further research.

\section{Conclusion}

In the present work we have evaluated the respective reactivity of a series of 5-bromoporphyrins bearing peripheral substituents with different electronic properties towards the nucleophilic attack using the widely available level of DFT calculations. Our objective was to expand the applicability of the tested rapid and reliable B3LYP 6-31G* method for the estimation of the reactivity of 5-bromoporphyrins towards nucleophiles. The analysis of the energy and localization of the unoccupied orbitals of the substrates allows estimation of the reactivity of the molecule without carrying out the complete DFT calculation of the reaction paths. We have demonstrated that B3LYP 6-31G* calculation of the relative energy and localization of frontier orbitals of the substrate molecule could be used as a method for the reliable prediction of the reactivity.

Acknowledgements. The authors are grateful to Russian Foundation for Basic Research (grant 17-53-16025) for financial support.

\section{References}

1. Alonso C.M.A., Barata J.F.B., Cavaleiro J.A.S., Faustino M.A.F., Monti D., Nardis S., Neves M.G.P.M.S., Pires S.M.G.,
Santos C.I.M., Smith K.M., Tome A.C., Serra V.I.V., Wojaczynski J. In: Synthesis and Modifications of Porphyrinoids (Paolesse R., Ed.) Springer Berlin Heidelberg, 2014. p. 1-301.

2. Beletskaya I.P., Tyurin V.S., Uglov A., Stern C., Guilard R. In: Handbook of Porphyrin Science (Guilard R., Kadish K.M., Smith K.M., Eds.) World Scientific Publishing, 2012. p. 81279.

3. Senge M.O., Bischoff I. Tetrahedron Lett. 2004, 45, 16471650 .

4. Senge M.O. Acc. Chem. Res. 2005, 38, 733-743.

5. Crossley M.J., King L.G. J. Chem. Soc., Perkin Trans. 1 1996, 1251.

6. Kalisch W.W., Senge M.O. Angew. Chem. Int. Ed. 1998, 37, 1107-1109.

7. Senge M.O., Kalisch W.W., Bischoff I. Chem. Eur. J. 2000, 6, 2721-2738.

8. Feng X., Senge M.O. Tetrahedron 2000, 56, 587-590.

9. Feng X., Senge M.O. J. Chem. Soc., Perkin Trans. 1 2001, 1030-1038.

10. Senge M.O., Hatscher S.S., Wiehe A., Dahms K., Kelling A. J. Am. Chem. Soc. 2004, 126, 13634-13635.

11. Fazekas M., Pintea M., Senge M.O., Zawadzka M. Tetrahedron Lett. 2008, 49, 2236-2239.

12. Ryan A.A., Plunkett S., Casey A., McCabe T., Senge M.O. Chem. Commun. 2014, 50, 353-355.

13. Crossley M.J., King L.G., Simpson J.L. J. Chem. Soc., Perkin Trans. 1 1997, 4, 3087-3096.

14. Crossley M.J., King L.G., Pyke S.M., Tansey C.W. J. Porphyrins Phthalocyanines 2002, 6, 685-694.

15. Balaban M.C., Eichhöfer A., Buth G., Hauschild R., Szmytkowski J., Kalt H., Balaban T.S. J. Phys. Chem. B 2008, 112, $5512-5521$.

16. Balaban M.C., Chappaz-Gillot C., Canard G., Fuhr O., Roussel C., Balaban T.S. Tetrahedron 2009, 65, 3733-3739.

17. Ostrowski S., Grzyb S. Tetrahedron Lett. 2012, 53, 6355-6357.

18. Grzyb S., Ostrowski S. Jordan J. Chem. 2012, 7, 231-237.

19. Devillers C.H., Hebié S., Lucas D., Cattey H., Clément S., Richeter S. J. Org. Chem. 2014, 79, 6424-6434.

20. Chen Q., Zhu Y., Fan Q., Zhang S., Zheng J. Org. Lett. 2014 16, 1590-1593.

21. Chappaz-Gillot C., Canard G., Andreoli F., Vanthuyne N., Giorgi M., Naubron J.-V., Monnier V., Rosas R., Roussel C., Balaban T.S. Eur. J. Org. Chem. 2012, 2012, 6526-6536.

22. Yamashita K., Kataoka K., Asano M.S., Sugiura K. Org. Lett. 2012, 14, 190-193.

23. Birin K.P., Gorbunova Y.G., Tsivadze A.Y., BessmertnykhLemeune A.G., Guilard R. Macroheterocycles 2012, 5, 338342.

24. Bruhn T., Witterauf F., Götz D.C.G., Grimmer C.T., Würtemberger M., Radius U., Bringmann G. Chem. Eur. J. 2014, 20, 3998-4006.

25. Michalak J., Birin K.P., Muniappan S., Ranyuk E., Enakieva Y.Y., Gorbunova Y.G., Stern C., Bessmertnykh-Lemeune A., Guilard R. J. Porphyrins Phthalocyanines 2014, 18, 35-48.

26. Birin K.P., Gorbunova Y.G., Tsivadze A.Y., BessmertnykhLemeune A.G., Guilard R. Eur. J. Org. Chem. 2015, 2015, 5610-5619.

27. Abdulaeva I.A., Birin K.P., Michalak J., Romieu A., Stern C., Bessmertnykh-Lemeune A., Guilard R., Gorbunova Y.G., Tsivadze A.Y. New J. Chem. 2016, 40, 5758-5774.

28. Birin K.P., Gorbunova Y.G., Tsivadze A.Y. $R S C A d v .2015,5$, 67242-67246.

29. Birin K.P., Poddubnaya A.I., Abdulaeva I.A., Gorbunova Y.G., Tsivadze A.Y. Dyes Pigm. 2018, in press. 